\title{
Investigation of Various Coating Resins for Optimal Anticorrosion and Mechanical Properties of Mild Steel Surface in NaCl Solution
}

\author{
Sandeep V. Gujjar, ${ }^{1}$ Nandini Nadar, ${ }^{2}$ Kanaram Choudhary, ${ }^{3}$ Anand M. Hunashyal, ${ }^{4}$ \\ Kiran Shahapurkar ${ }^{(D)}{ }^{5}$ M. A. Mujtaba ${ }^{(D)},{ }^{6}$ Mohammed Asadullah, \\ Manzoore Elahi M. Soudagar $\mathbb{D}^{6,8}$ T. M. Yunus Khan, ${ }^{9}$ Khadiga Ahmed Ismail, ${ }^{10}$ \\ and Ashraf Elfasakhany ${ }^{11}$ \\ ${ }^{1}$ Department of Civil Engineering, Pillai HOC College of Engineering and Technology, Dist. Raigad, Rasayani 410207, \\ Maharashtra, India \\ ${ }^{2}$ Department of Mechanical Engineering, B.M.S.Institute of Technology and Management, Bangalore 64, Karnataka, India \\ ${ }^{3}$ Rustomjee Academy for Global Careers, Dahanu Road (E), 401602 Mumbai, Maharashtra, India \\ ${ }^{4}$ Department of Civil Engineering, BVB College of Engineering and Technology, KLE Technological University, \\ Hubli 580021, India \\ ${ }^{5}$ School of Mechanical, Chemical and Materials Engineering, Adama Science and Technology University, Adama 1888, Ethiopia \\ ${ }^{6}$ Department of Mechanical Engineering, Faculty of Engineering, University of Malaya, Kuala Lumpur 50603, Malaysia \\ ${ }^{7}$ Mechanical Engineering Department, Faculty of Engineering, Lords Institute of Engineering and Technology, Hyderabad, India \\ ${ }^{8}$ Department of Mechanical Engineering, School of Technology, Glocal University, Delhi-Yamunotri Marg, SH-57, Mirzapur Pole, \\ Saharanpur District, Uttar Pradesh 247121, India \\ ${ }^{9}$ Department of Mechanical Engineering, College of Engineering, King Khalid University, Abha 61421, Saudi Arabia \\ ${ }^{10}$ Department of Clinical Laboratory Sciences, College of Applied Medical Sciences, Taif University, P.O. Box 11099, Taif 21944, \\ Saudi Arabia \\ ${ }^{11}$ Mechanical Engineering Department, College of Engineering, Taif University, P.O. Box 11099, Taif 21944, Saudi Arabia
}

Correspondence should be addressed to Kiran Shahapurkar; kiranhs1588@astu.edu.et

Received 29 September 2021; Revised 21 January 2022; Accepted 29 January 2022; Published 28 February 2022

Academic Editor: P Ganeshan

Copyright (c) 2022 Sandeep V. Gujjar et al. This is an open access article distributed under the Creative Commons Attribution License, which permits unrestricted use, distribution, and reproduction in any medium, provided the original work is properly cited.

The primary objective of the research was to investigate the ideal resin coating on the mild steel surface among various resin coatings which are in use. These resin coatings are used as an anti-corrosive material for mild steel surfaces with enhanced mechanical properties. The resins (epoxy, polyurethane, polyester, and phenolic) on mild steel surface were applied by the pneumatic spray coating method. In addition, immersion test and salt spray test methods were followed using sodium chloride $(\mathrm{NaCl})$ solution. Furthermore, the rate of corrosion and mechanical properties of mild steel coated with different resins was evaluated by conducting various experiments (immersion test, salt spray test, tensile strength test, and scratch hardness test) and was compared with a bare mild steel surface. The results of the current research showed that the mild steel surface coated with epoxy resin was found to be the most effective corrosion resistance material with better mechanical properties compared to other tested mild steel resin-coated surfaces.

\section{Introduction}

Mild steel plays a vital role in the lifespan of a civil engineering structure, and usually, the performance of carbon steels is hampered by its surface features such as surface texture and surface energy due to corrosion $[1,2]$. It is causing a serious issue in the field of the construction industry due to loss of structural strength, reduced bond strength, ductility, and shear capacity $[3,4]$. To avoid the corrosion problem and increase the tensile strength of mild 
steel, many attempts have been made so far by surface coating using inorganic coating, paints, resins, alloying additions, and many others. Different types of resins have been studied individually in the literature and found to be very effective in controlling the corrosion of civil structures. Many researchers have evaluated the anticorrosion properties of various types of resin coatings on mild steel surfaces. Epoxy-silane hybrid coatings have coating ratios between 1 to $3 \mathrm{wt}$. $\%$ on galvanized steel which has improved the adhesion and corrosion behavior of the surface, whereas a further add up to $5 \mathrm{wt} . \%$ resulted in reducing its corrosion/adhesion performance [5]. The cathodic delamination of polyurethane/multiwalled carbon nanotube composite coatings up to $0.5 \mathrm{wt} . \%$ on steel substrate has increased the corrosion protective performance in the $\mathrm{NaCl}$ solution proved by the scanning Kelvin probe (SKP) results [6]. Corrosion-performance evaluation studies in a $3.5 \mathrm{wt} . \% \mathrm{NaCl}$ electrolyte conducted via EIS and potentiodynamic polarization tests have shown that the MWCNT in polypyrrole (PPY) coating has considerably reduced the corrosion rate. Interestingly, PPY/MWCNT-COO-functionalized nanocomposite provided a higher corrosion resistance coating than PPY/MWCNT alone [7]. Mild steel coated with MWCNT/epoxy nanocomposite (0.75 wt.\%) revealed a decrease in the corrosion rate up to $2.5 \times 10^{3} \mathrm{MPY}$ and the protection efficiency increased up to $99.99 \%$ [8]. From the electrochemical measurements, it was found that the corrosion resistance of carbon steel has significantly improved by the hybrid coating in a $0.75 \%$ saline solution [9]. From another experimental study, it was observed that about 0.1 wt.\% graphene oxide (GO) was the appropriate GO content to prepare nanocomposites of GO-epoxy with an optimum corrosion resistance [10].

It was found that MWCNTs were dispersed uniformly in the PU matrix from 4 to 6 wt. \%, no aggregation and precipitation phenomena were observed in the fast spraying process [11]. B. Ramezanzadeh et al. [12] proved a coating of 0.1wt.\% GO and PI-GO nanosheets to the polyurethane resin have enhanced its corrosion protection properties. Figure 1 shows the synthesis of waterborne epoxy resin (WEP) coating and fluorinated graphene (FG)-modified WEP coatings [13].

Research studies on individual resins coatings for mild steel surfaces have targeted better mechanical, physical, water, heat, resistance, and antimicrobial activity. However, very few research works were focused on identifying the optimum resin that produced the best anticorrosion and mechanical properties on the mild steel surface. Hence, the objective of the present study was to determine the ideal resin with anticorrosion and enhanced mechanical properties for a mild steel substrate. The resins (polyester, epoxy, polyurethane, and phenolic) were prepared by using the respective accelerator, hardener, and thinners. The prepared resins were used as coatings on the fabricated mild steel surface. Furthermore, the surface was subjected to corrosion analysis by performing an immersion and salt spray test. In addition, the tensile strength and scratch hardness tests were performed to evaluate the mechanical properties of the mild steel surface. The degree of anticorrosion performance and morphological characteristics of epoxy [5, 8-10, 14-24], polyurethane $[6,11,12,25,26]$, phenolic $[25,27,28]$, and polyester resins [29] as surface coatings for mild steel were compared and discussed.

\section{Experimental Procedure}

2.1. Materials. Polyurethane resin (FINESTER-1100) is a two-component polyurethane composition based on acrylic polyol and isocyanate. Epoxy resin (FINE COAT-EP 200A \& B) is a two-component epoxy clear lacquer, cured with polyamide hardener. It cures at room temperature (above $10^{\circ} \mathrm{C}$ ). Polyester Resin (PS) (FINESTER - 1100) is a medium viscosity modified ISO polyester resin. Phenolic Resin (PH) INSUFINE-VI 610 is an impregnating varnish based on alkyd and phenolic resins. The epoxy, polyurethane, polyester, and phenolic resins were purchased from the Fine Finish Organics Pvt. Ltd., Navi Mumbai, India. Mild steel panels were purchased from Shubh M L Shah and Sons Steel Pvt. Ltd., Mumbai, India. A pneumatic spray gun was purchased from Burhani hardware, Dahanurd, India. The technical specifications of epoxy resin, polyurethane resin, polyester resin, and phenolic resins are listed in Table 1.

2.2. Preparation of Resins and Mild Steel Surface. The polyester resin coating was prepared by adding $10 \mathrm{gm}$ of polyester resin (PS) (FINESTER-1100) with accelerator-1100 and catalyst-1100 in the ratio of $100: 1: 1$ by weight, and further, $20 \mathrm{~mL}$ of the thinner 643 was added for curing purposes (Figure 1). The curing was performed at room temperature between 25 and $40^{\circ} \mathrm{C}$. The epoxy resin coating was prepared by first adding $10 \mathrm{gm}$ of FINE COAT (EP 200 A) with EP $200 \mathrm{~B}$ hardener in the ratio of $2: 1$ and then the thinner of grade 643 was added $(20 \mathrm{ml})$ (Figure 1). Polyurethane coating was prepared by first adding 10 gm of polyurethane resin (PU) (PU $500 \mathrm{~A}$ ) with PU $500 \mathrm{~B}$ hardener $(1: 1)$ ratio (Figure 2). Furthermore, for phenolic resin coating, $10 \mathrm{gm}$ of phenolic resin (INSUFINE-VI610) was taken for the coating purpose (Figure 2).

The surface of mild steel sheets was blasted with emery paper 80 grit size and washed with acetone to clean and remove the oxides present on the surface of mild steel. Furthermore, the specimens were dried at room temperature for 1 hour and were coated with resin. The prepared epoxy, polyurethane, polyester, and phenolic resins were sprayed on the surface of mild steel through a pneumatic spray gun. Finally, the coated mild steel specimens were dried at room temperature for 48 hours and annealed at $150^{\circ} \mathrm{C}$ for 1 hour in a hot-air oven. The distance maintained between the spraying gun and the specimen was about $100-150 \mathrm{~mm}$ to obtain the required thickness $(160-180 \mu \mathrm{m})$ of the coating layer. Mild steel specimens coated with the different resin of $12 \mathrm{~mm}$ diameter were cut to a length of $300 \mathrm{~mm}$ for performing a tensile test. Furthermore, a flat mild steel specimen of size $125 \times 60 \times 6 \mathrm{~mm}^{3}$ was used for the scratch hardness test. 


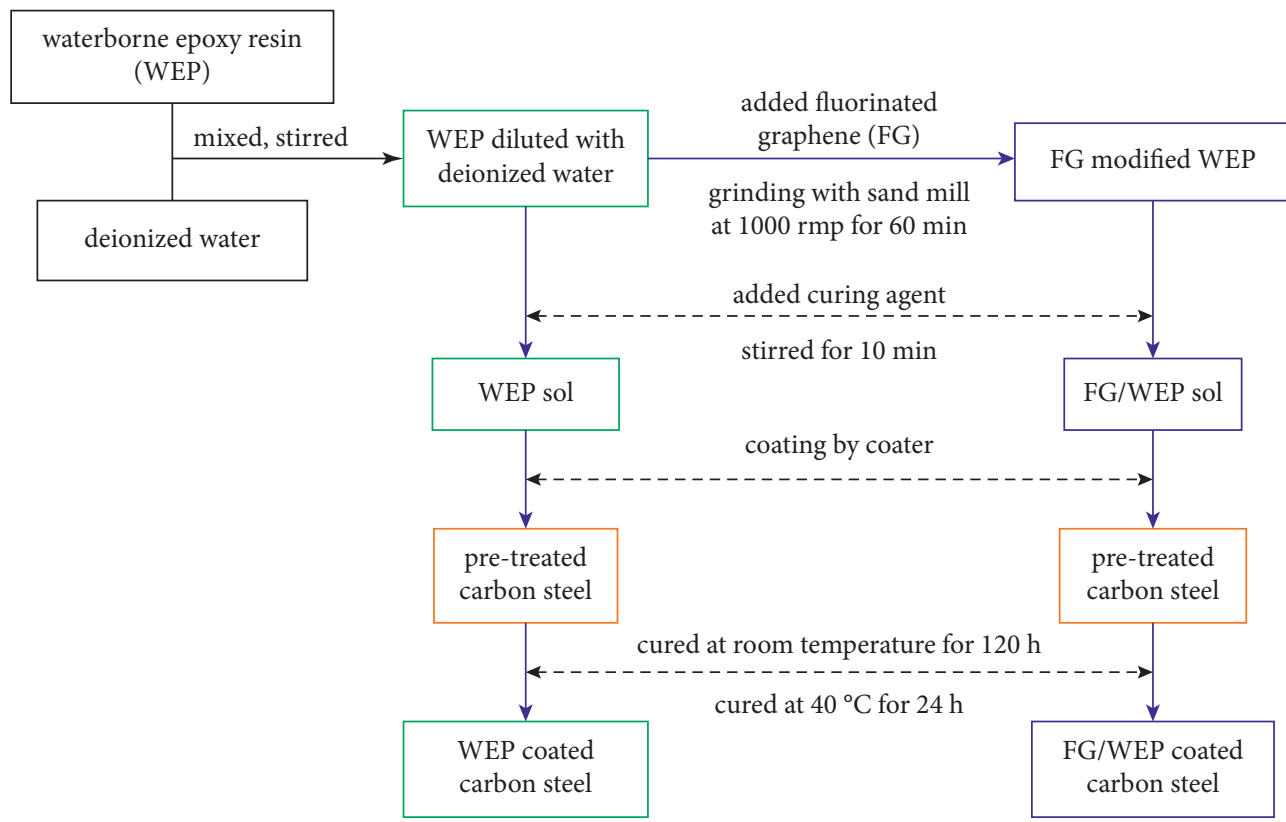

FIGURE 1: Synthesis of waterborne epoxy resin (WEP) coating and fluorinated graphene (FG)-modified WEP coatings [13].

Table 1: Technical specifications of resin.

\begin{tabular}{|c|c|c|c|c|}
\hline \multirow{2}{*}{$\begin{array}{l}\text { Sl. } \\
\text { No. }\end{array}$} & \multicolumn{4}{|c|}{ Resin specifications } \\
\hline & Epoxy & Polyurethane & Polyester & Phenolic \\
\hline 1 & $\begin{array}{l}\text { Color: clear and can be dyed as per the } \\
\text { requirement }\end{array}$ & $\begin{array}{l}\text { Color: colorless (PU500/A and } \\
\text { PU500/B) }\end{array}$ & $\begin{array}{l}\text { Viscosity range, } \\
\text { MPa.s.@30 } \\
\text { 300-500 }\end{array}$ & $\begin{array}{l}\text { Color: } \\
\text { yellow }\end{array}$ \\
\hline 2 & Finish: glossy & Finish: glossy & $\begin{array}{l}\text { Acid value, mg of } \mathrm{KOH} / \\
\text { g: } 10-20\end{array}$ & $\begin{array}{c}\text { Viscosity @ } 25^{\circ} \mathrm{C} \text { (B4 flow } \\
\text { cup): } \\
30-40 \mathrm{sec}\end{array}$ \\
\hline 3 & Mixing ratio & $\begin{array}{c}\text { Mixing ratio (PU500A : PU500B) } \\
1: 1 \text { (by weight) }\end{array}$ & Color, gardener: & Finish: \\
\hline 4 & $\begin{array}{c}\text { Base : hardener }=2: 1 \text { (by volume) } \\
\text { Pot life } \\
14-16 \text { hours } @ 30^{\circ} \mathrm{C}\end{array}$ & $\begin{array}{l}\text { Viscosity at } 25^{\circ} \mathrm{C}: \\
15 \pm 5 \mathrm{MPa} \cdot \mathrm{s}\end{array}$ & $\begin{array}{l}<1 \\
\text { Specific gravity: } \\
1.10-1.12\end{array}$ & $\begin{array}{l}\text { glossy } \\
\text { Bond strength, at } 30^{\circ} \mathrm{C} \text { : } \\
25\end{array}$ \\
\hline 5 & $\begin{array}{l}\text { Theoretical covering capacity: } 12 \text { sq.m./ } \\
\text { lit @25 microns dft. }\end{array}$ & $\begin{array}{l}\text { Solid content: } \\
\qquad 60 \pm 2 \%\end{array}$ & Volatile content (max.): & $\begin{array}{l}\text { Volume resistivity at } \\
30^{\circ} \mathrm{C} \text { : } \\
1-1.5 \times 10^{16} \mathrm{~cm} \text { after } \\
\text { immersion }\end{array}$ \\
\hline 6 & $\begin{array}{l}\text { Application method: } \\
\text { air-assisted/airless spray/brush }\end{array}$ & $\begin{array}{l}\text { Application method: } \\
\text { brush/Spray }\end{array}$ & - & - \\
\hline 7 & - & $\begin{array}{l}\text { Continuous operating } \\
\text { temperature: } \\
155^{\circ} \mathrm{C}\end{array}$ & - & - \\
\hline
\end{tabular}

${ }^{*}$ denotes as supplied by the manufacturer.

2.3. Morphological Studies. The corrosion behavior on the surface of mild steel specimens coated with different resins was evaluated by morphological studies using a field emission scanning electron microscope (FESEM). The corroded surface was gold coated by a sputtering unit and FESEM was operated at an accelerating voltage of $20 \mathrm{kV}$.
2.4. Corrosion Studies by Immersion Test. The corrosion resistance properties of epoxy, polyurethane, polyester, and phenolic resins coated on mild steel surface were subjected to immersion method. The resin-coated samples were immersed in the aqueous $3.5 \% \mathrm{NaCl}$ solution for 336 hours, and the corrosion rate was determined by the weighing 


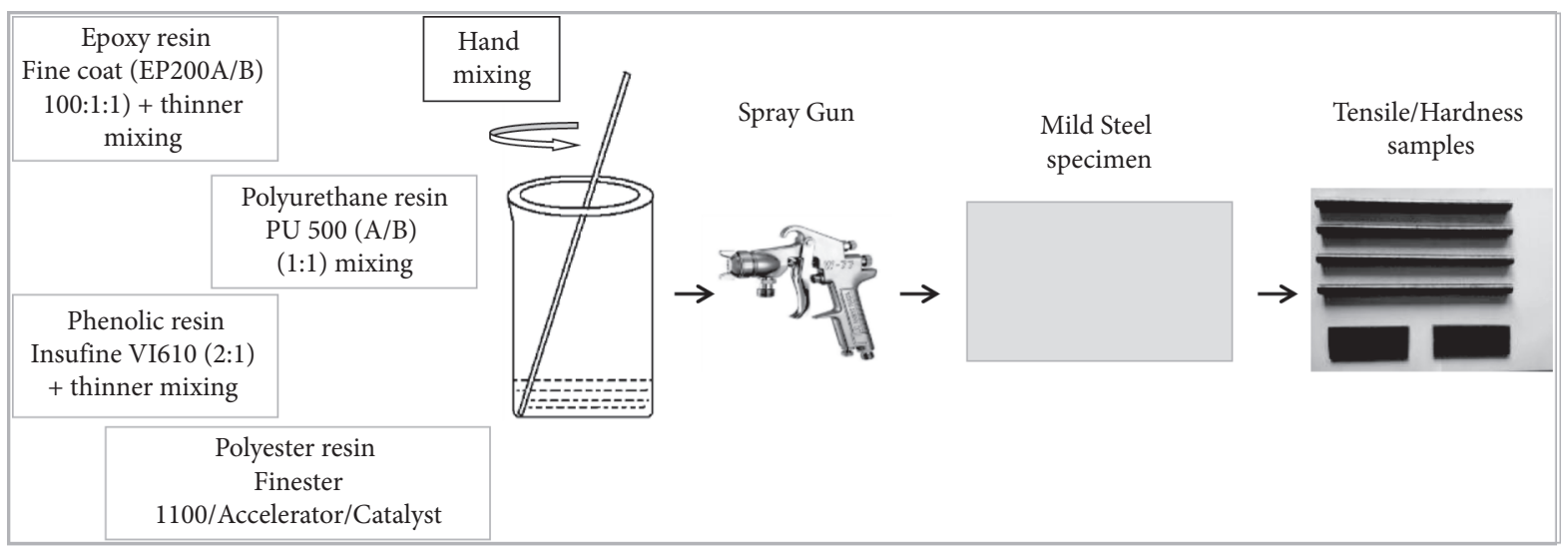

FIGURE 2: Schematic representation of the coating process of mild steel specimen.

method. The weight of the steel sample coated with a resin was measured before and after immersion to determine the corrosion rate. A minimum of three samples per composition were tested for obtaining an averaged corrosion response. The corrosion resistance properties obtained for bare and resin-coated mild steel samples are listed in Table 2.

\subsection{Mechanical Properties}

2.5.1. Tensile Strength Test (A370: 2017). The effects of epoxy, polyurethane, polyester, and phenolic resins coated on mild steel surfaces were studied to determine their tensile strength properties. The tensile test was carried out by using a universal testing setup (A370:2017) to determine its ultimate tensile strength, yield load, and yield stress. For ensuring repeatability of the results, three samples were tested for each category of the resin-coated mild steel specimens. The ultimate tensile strength of plain mild steel and samples coated with different resins are presented in Table 2.

2.5.2. Scratch Hardness Test. The flat mild steel sample of a dimension of $120 \times 60 \mathrm{~mm}^{2}$ was subjected to scratch hardness testing according to IS 101 (Part-5, Sec.2):1988. The minimum load required to cause the failure was noted as the hardness of the resin-coated mild steel surface. All the resincoated specimens were tested in a batch of 3 samples to obtain accurate results, which are recorded and reported in Table 2.

\section{Results and Discussion}

The cumulative result of the obtained average values of corrosion resistance, ultimate tensile strength, toughness, and scratch hardness test of the bare and resin-coated mild steel specimens are listed in Table 2.

3.1. Corrosion Properties of Resin Coating. The average value of the corrosion resistive properties obtained from the immersion test for all the types of resin-coated mild steel samples is plotted as shown in Figure 3. The epoxy resin- coated mild steel sample exhibited the maximum corrosion resistivity of $4102.29 \mathrm{mil}$, followed by phenolic resin (1414.97 mil), polyester resin $(1233.38 \mathrm{mil})$, and polyurethane resin (635.85 mil) coated samples in comparison to the uncoated mild steel surface, as shown in Figure 3. It was observed also that the epoxy resin-coated samples have yielded the maximum corrosion resistance property, which can be accounted for its chemical structure that induces high chemical resistivity and good adhesion properties under a wide range of corrosive conditions. This enables the mild steel specimen to remain intact even in highly humid and corrosive conditions.

\subsection{Mechanical Properties}

3.2.1. Stress-Strain Curve (A370: 2017). Figure 4 depicts the stress-strain curve for different resins coated mild steel specimens. This curve is utilized for evaluating the tensile strength and toughness of the resin-coated samples. It can be observed that the ratio of stress and strain was proportional for all the types of resin-coated mild steel samples under small applied tensile force. A straight line between zero to stress value around $300 \mathrm{MPa}$ can be also observed. When the force applied is greater, the samples experience elastic deformation as seen from curves. Further loading induces plastic deformation in the samples and results in a fracture. It is observed that the epoxy-coated mild steel specimen has yielded higher ultimate strength in comparison to other samples due to the difference in the elastic modulus between the two materials that make the best microstructure design in handling the applied load gradually.

3.2.2. Tensile Strength Test (A370:2017). The average value of ultimate tensile strength obtained from UTM for all the types of resin-coated samples in comparison to plain mild steel specimen is plotted, as shown in Figure 4(a). The samples coated with epoxy resin showed a maximum ultimate tensile strength of $505.82 \mathrm{~N} / \mathrm{mm}^{2}$, followed by phenolic resin $\left(491.47 \mathrm{~N} / \mathrm{mm}^{2}\right)$, polyurethane resin $\left(485.63 \mathrm{~N} / \mathrm{mm}^{2}\right)$, and polyester resin $\left(474.54 \mathrm{~N} / \mathrm{mm}^{2}\right)$ in comparison with mild steel surface, as shown in Figure 5(a). The samples 
TABLE 2: Anticorrosion and mechanical test results.

\begin{tabular}{|c|c|c|c|c|c|}
\hline $\begin{array}{l}\text { Sl. } \\
\text { No. }\end{array}$ & Specimen & $\begin{array}{c}\text { Corrosion resistance by resin } \\
\text { (mils) }\end{array}$ & $\begin{array}{l}\text { Ultimate tensile strength }(\mathrm{N} / \\
\left.\mathrm{mm}^{2}\right)\end{array}$ & $\begin{array}{c}\text { Toughness (N/ } \\
\mathrm{mm})\end{array}$ & $\begin{array}{c}\text { Scratch hardness } \\
(\mathrm{mg})\end{array}$ \\
\hline 1 & Plain mild steel & - & $456.23 \pm 9.12$ & - & $150.00 \pm 3$ \\
\hline 2 & $\begin{array}{l}\text { Polyurethane } \\
\text { resin }\end{array}$ & $635.85 \pm 12.71$ & $485.63 \pm 9.71$ & 5893.224 & $800.00 \pm 16$ \\
\hline 3 & Epoxy resin & $4102.29 \pm 82.04$ & $505.82 \pm 10.12$ & 7057.32 & $700.00 \pm 14$ \\
\hline 4 & Polyester resin & $1233.38 \pm 24.66$ & $474.54 \pm 9.49$ & 6738.417 & $300.00 \pm 6$ \\
\hline 5 & Phenolic resin & $1414.97 \pm 28.29$ & $491.47 \pm 9.82$ & 5394.345 & $300.00 \pm 6$ \\
\hline
\end{tabular}

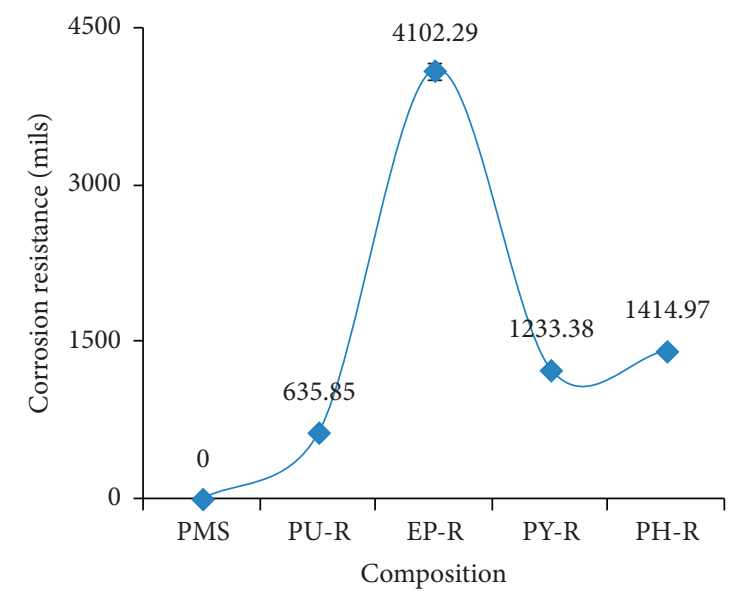

Figure 3: The corrosion resistance of the samples.

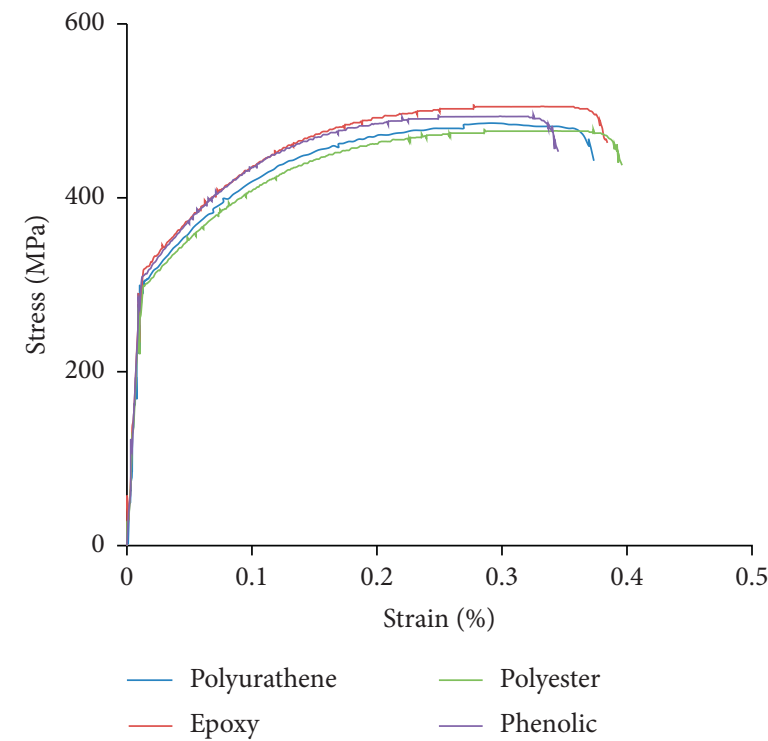

FIGURE 4: Representative stress-strain curves of samples coated with different polymer resins.

coated with epoxy resin showed the maximum percentage of increase in ultimate tensile strength in comparison to mild steel samples by $9.80 \%$. It is because of the multicoordination sites formed by the hydroxyl and amine groups that form a $3 \mathrm{D}$ cross-linked polymeric network for metals [30]. The good physical properties of epoxy resin such as toughness, flexibility, and abrasion resistance are superior to almost all thermoplastics in elevated temperature performance, whereas phenolic resin showed $7.72 \%$, polyurethane showed $6.05 \%$, and polyester resin revealed the least increase of $3.85 \%$ w.r.t the mild steel samples without coating.

3.2.3. Toughness Test of Mild Steel Samples. The toughness of resin-coated mild steel specimens is illustrated in 


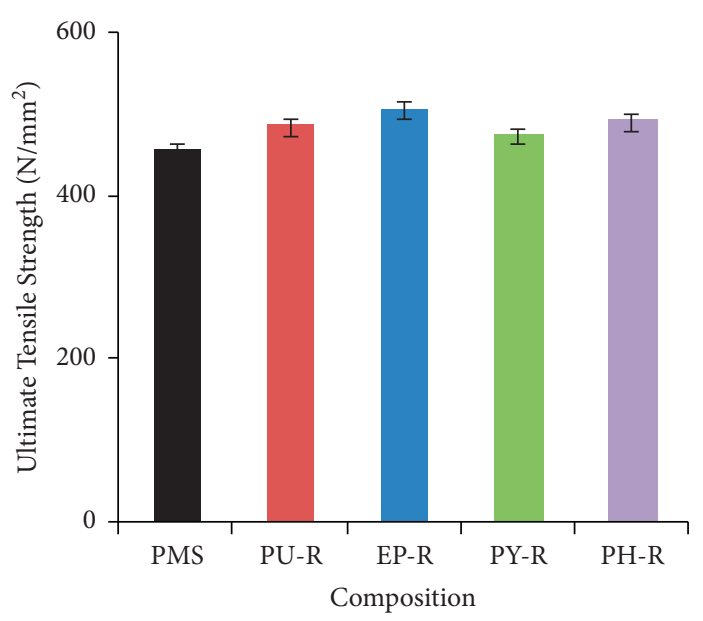

(a)

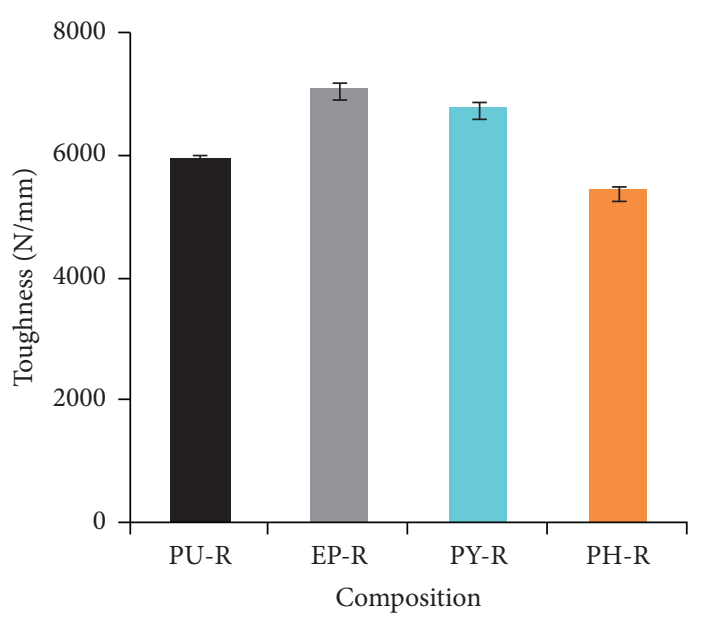

(b)

Figure 5: Experimentally calculated (a) ultimate tensile strength and (b) toughness of samples.

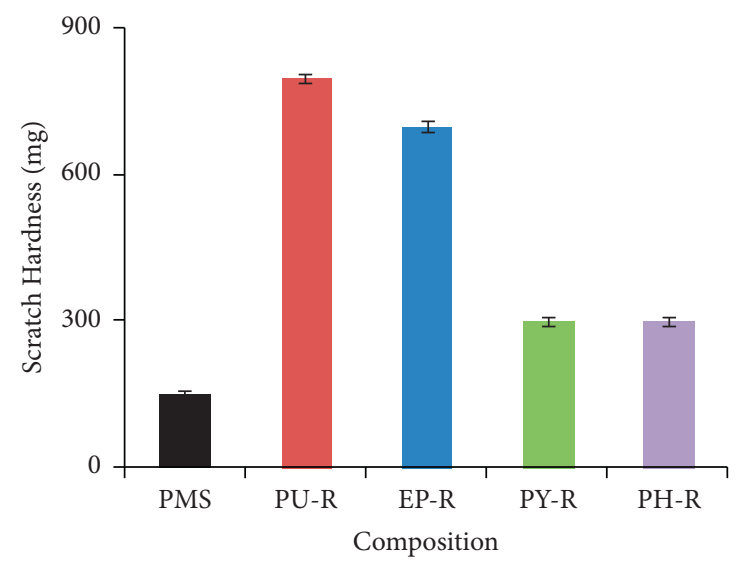

FIGURE 6: Scratch hardness of samples.

Figure 5(b). It can be observed that the toughness value of the resin-coated mild steel specimens was comparatively higher than the bare mild steel sample. The epoxy resincoated sample exhibited the highest toughness index with $7057.32 \mathrm{~N} / \mathrm{mm}$ compared to the phenolic resin-coated sample with $5394.345 \mathrm{~N} / \mathrm{mm}$, polyurethane resin-coated sample with $5893.224 \mathrm{~N} / \mathrm{mm}$, and polyester resin-coated sample with $6738.417 \mathrm{~N} / \mathrm{mm}$. The enhancement in the toughness result for the epoxy-coated samples is due to the two-component epoxy clear lacquer, cured with polyamide hardener and good comparative tracking index $>500 \mathrm{~V}$. This is due to the extension of the $3 \mathrm{D}$ polymeric network by the hydroxyl and amine group present in the epoxy matrix [30]. In addition, the physical properties of epoxy resin are comparatively better than polyurethane, polyester, and phenolic resins.

3.2.4. Scratch Hardness Test. The hardness test results of bare mild steel and various types of resin-coated samples are shown in Figure 6. The scratch hardness of the polyurethane resin-coated sample revealed the maximum hardness (800mg), followed by an epoxy resin-coated sample with $700 \mathrm{mg}$. Polyester and phenolic resin-coated samples showed the least increase of hardness $(300 \mathrm{mg}$ ) in comparison to pure mild steel samples. The scratch hardness of polyurethane resin-coated samples yielded the highest because the layer of polymer used here can protect the base material from corrosion, weathering, abrasion, and other processes that would protect the material from degradation over time.

3.3. Morphology. The morphology of various types of resincoated mild steel samples before and after corrosion areas is depicted in Figure 7. Figures 7(a) and 7(b) show the images of FESEM of the polyurethane resin before and after the mild steel samples were exposed to corrosion. Figure 6(b) depicts the corrosion developed on the surface. Figures 7(c) and 7(d) show the images of epoxy resin-coated samples. Figure $7(d)$ indicates that epoxy resin has successfully protected the mild steel surface with minimum rust on its surface. Figures $7(\mathrm{e})$ and $7(\mathrm{f})$ show polyester resin-coated samples before and after oxidization, and Figure $7(\mathrm{f})$ indicates a high level of 


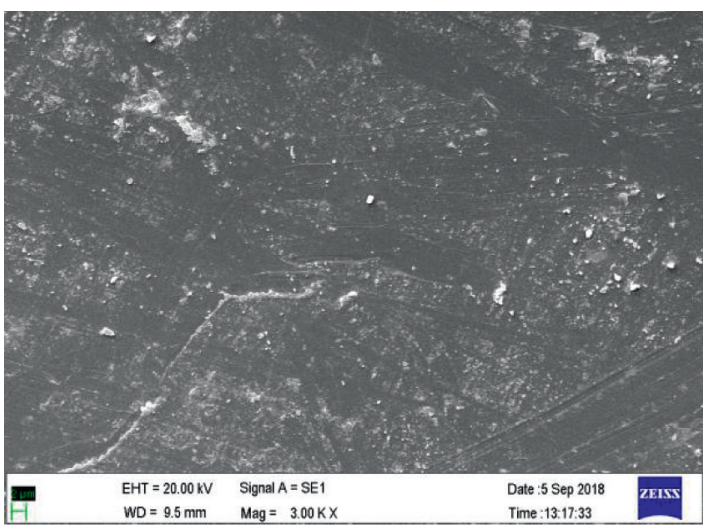

(a)

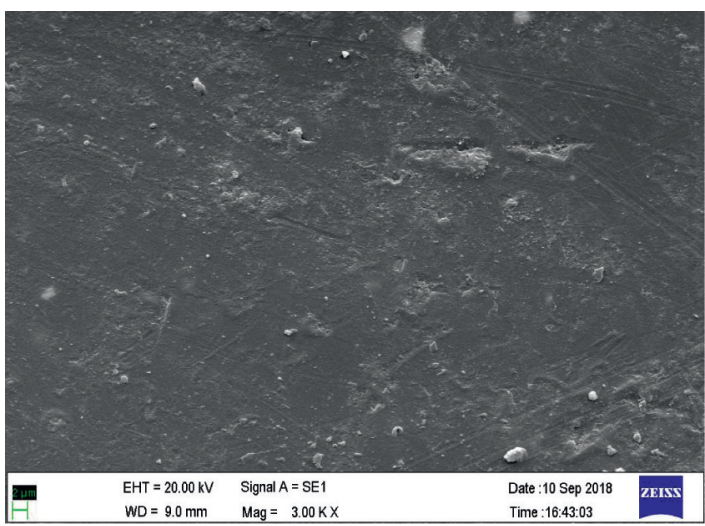

(c)



(e)

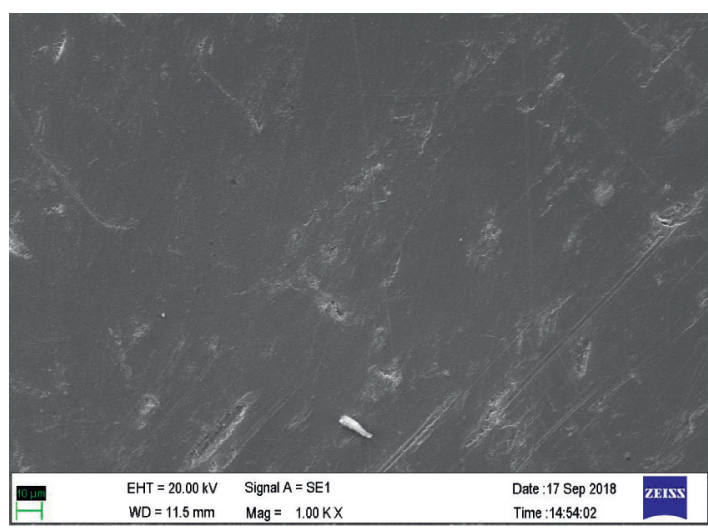

(g)

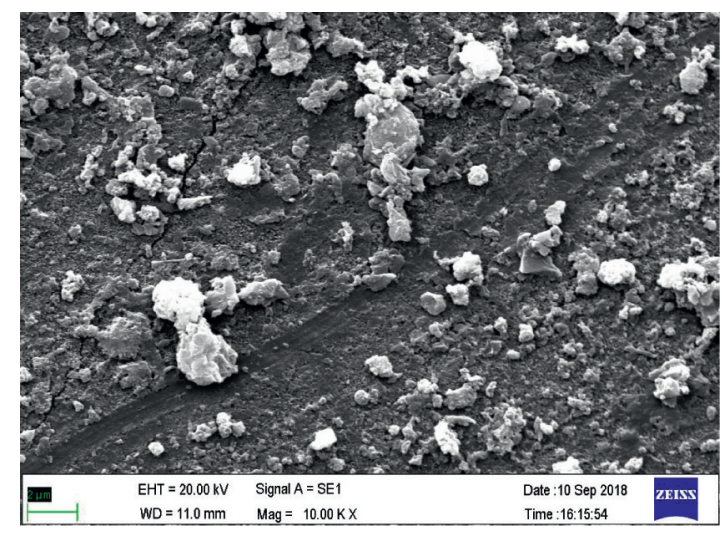

(b)

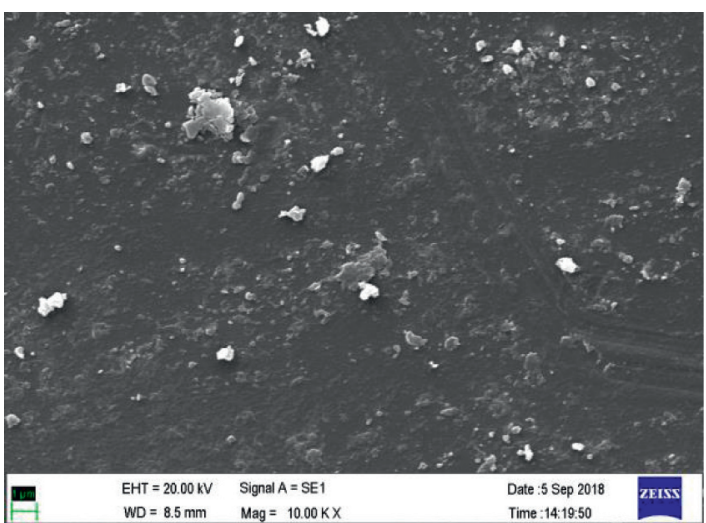

(d)

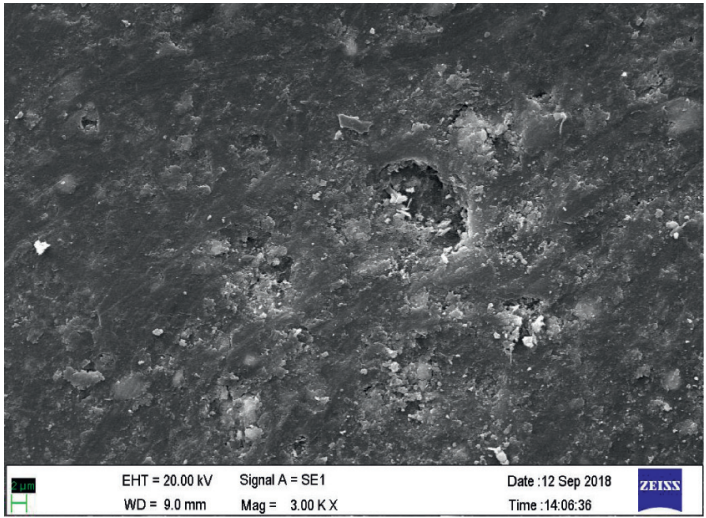

(f)

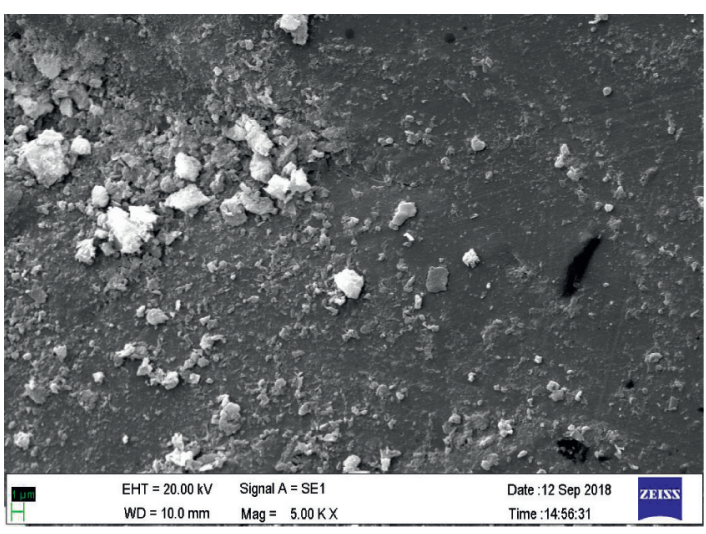

(h)

FIGURE 7: FESEM images of samples coated with polyurethane resin (a) before corrosion and (b) after corrosion, epoxy resin (c) before corrosion and (d) after corrosion, polyester resin (e) before corrosion and (f) after corrosion, and phenolic resin (g) before corrosion and (h) after corrosion. 
corrosion. It is also worthy to notice the rusted surface (Figure 7(h)) on the mild steel sample coated with phenolic resin earlier after exposure to corrosion in comparison to before exposure (Figure $7(\mathrm{~g})$ ). It can be observed that the mild steel samples coated with the epoxy resin (Figure 7(d)) showed the lowest corrosion in comparison to polyurethane, polyester, and phenolic resins. The morphology results are in agreement with the results of the ultimate tensile strength and corrosion resistive in which the epoxy resin-coated mild steel specimens yielded the best performing results.

\section{Conclusions}

In summary, the outcomes of this study are as follows:

(i) Mild steel samples coated with epoxy resin exhibited very good resistance to corrosion. There was a remarkable increase in the rate of tensile strength of mild steel specimens coated with the epoxy resin.

(ii) It was found that the surface morphology of mild steel specimens with epoxy resin coating exhibits minute rust particles compared with other resins and plain mild steel.

(iii) Scratch hardness of polyurethane resin-coated mild steel specimen yielded better hardness in comparison to other mild steel specimens due to the presence of acrylic polyol and isocyanate. This induces better hardness to the coating surface. However, the corrosion resistance and tensile property are less than the epoxy coated samples.

(iv) FESEM analysis shows the samples coated with epoxy resin observed to have the least corroded surface compared with the other resin-coated surfaces.

(v) Since epoxy resin FINECOAT-EP 200 is a twocomponent epoxy clear lacquer, cured with polyamide hardener, coated samples showed superior results in comparison with the polyurethane, phenolic, and polyester resins. Epoxy resin is the most suitable resin for surface coating of mild steel to shield from corrosion and also to enhance mechanical properties.

\section{Data Availability}

The data used to support the findings of this study are included within the article.

\section{Conflicts of Interest}

The authors declare that they have no conflicts of interest.

\section{Acknowledgments}

The authors extends his appreciation to the Deanship of Scientific Research at King Khalid University for funding this work through research groups program under grant number (R.G.P 1/221/41). This study was supported by Taif University Researchers Supporting Project Number (TURSP-2020/40), Taif University, Taif, Saudi Arabia.

\section{References}

[1] R. K. Gupta, M. Malviya, C. Verma, and M. A. Quraishi, "Aminoazobenzene and diaminoazobenzene functionalized graphene oxides as novel class of corrosion inhibitors for mild steel: experimental and DFT studies," Materials Chemistry and Physics, vol. 198, pp. 360-373, 2017.

[2] H. Eivaz Mohammadloo, S. M. Mirabedini, and H. PezeshkFallah, "Microencapsulation of quinoline and cerium based inhibitors for smart coating application: anti-corrosion, morphology and adhesion study," Progress in Organic Coatings, vol. 137, Article ID 105339, 2019.

[3] A. Khorram, "Microstructural evolution of laser clad Stellite 31 powder on Inconel 713 LC superalloy," Surface and Coatings Technology, vol. 423, Article ID 127633, 2021.

[4] M. Taheri, J. E. Jam, M. H. Beni, A. Khorram, S. F. KashaniBozorg, and M. J. Torkamany, "The effect of service temperature on the impact strength and fracture toughness of GTD-111 superalloy," Engineering Failure Analysis, vol. 127, Article ID 105507, 2021.

[5] S. Bera, T. K. Rout, G. Udayabhanu, and R. Narayan, "Waterbased \& eco-friendly epoxy-silane hybrid coating for enhanced corrosion protection \& adhesion on galvanized steel," Progress in Organic Coatings, vol. 101, pp. 24-44, 2016.

[6] N. W. Khun and G. S. Frankel, "Cathodic delamination of polyurethane/multiwalled carbon nanotube composite coatings from steel substrates," Progress in Organic Coatings, vol. 99, pp. 55-60, 2016.

[7] A. Davoodi, S. Honarbakhsh, and G. A. Farzi, "Evaluation of corrosion resistance of polypyrrole/functionalized multiwalled carbon nanotubes composite coatings on $60 \mathrm{Cu}-40 \mathrm{Zn}$ brass alloy," Progress in Organic Coatings, vol. 88, pp. 106-115, 2015.

[8] A. Kumar, P. K. Ghosh, K. L. Yadav, and K. Kumar, “Thermomechanical and anti-corrosive properties of MWCNT/epoxy nanocomposite fabricated by innovative dispersion technique," Composites Part B: Engineering, vol. 113, pp. 291-299, 2017.

[9] W. Shen, L. Feng, X. Liu et al., "Multiwall carbon nanotubesreinforced epoxy hybrid coatings with high electrical conductivity and corrosion resistance prepared via electrostatic spraying," Progress in Organic Coatings, vol. 90, pp. 139-146, 2016.

[10] S. Pourhashem, M. R. Vaezi, A. Rashidi, and M. R. Bagherzadeh, "Exploring corrosion protection properties of solvent based epoxy-graphene oxide nanocomposite coatings on mild steel," Corrosion Science, vol. 115, pp. 78-92, 2017.

[11] G. Li, L. Feng, P. Tong, and Z. Zhai, "The properties of MWCNT/polyurethane conductive composite coating prepared by electrostatic spraying," Progress in Organic Coatings, vol. 90, pp. 284-290, 2016.

[12] B. Ramezanzadeh, E. Ghasemi, M. Mahdavian, E. Changizi, and M. H. Mohamadzadeh Moghadam, "Covalently-grafted graphene oxide nanosheets to improve barrier and corrosion protection properties of polyurethane coatings," Carbon, vol. 93, pp. 555-573, 2015. 
[13] B. Dou, H. Xiao, X. Lin et al., "Investigation of the anticorrosion properties of fluorinated graphene-modified waterborne epoxy coatings for carbon steel," Coatings, vol. 11, no. 2, p. 254, 2021.

[14] V. K. Srivastava, "Enhancement of elastic modulus of epoxy resin with carbon nanotubes," World Journal of Nano Science and Engineering, vol. 01, no. 1, pp. 1-6, 2011.

[15] S. Ammar, K. Ramesh, B. Vengadaesvaran, S. Ramesh, and A. K. Arof, "Amelioration of anticorrosion and hydrophobic properties of epoxy/PDMS composite coatings containing nano $\mathrm{ZnO}$ particles," Progress in Organic Coatings, vol. 92, pp. 54-65, 2016.

[16] S. Park and M. Shon, "Effects of multi-walled carbon nano tubes on corrosion protection of zinc rich epoxy resin coating," Journal of Industrial and Engineering Chemistry, vol. 21, pp. 1258-1264, 2015.

[17] M. Rostami, S. Rasouli, B. Ramezanzadeh, and A. Askari, "Electrochemical investigation of the properties of Co doped $\mathrm{ZnO}$ nanoparticle as a corrosion inhibitive pigment for modifying corrosion resistance of the epoxy coating," Corrosion Science, vol. 88, pp. 387-399, 2014.

[18] W. Xia, H. Xue, J. Wang et al., "Functionlized graphene serving as free radical scavenger and corrosion protection in gamma-irradiated epoxy composites," Carbon, vol. 101, pp. 315-323, 2016.

[19] Z. Yu, H. Di, Y. Ma et al., "Preparation of graphene oxide modified by titanium dioxide to enhance the anti-corrosion performance of epoxy coatings," Surface and Coatings Technology, vol. 276, pp. 471-478, 2015.

[20] A. Talo, P. Passiniemi, O. Forsén, and S. Yläsaari, "Polyaniline/epoxy coatings with good anti-corrosion properties," Synthetic Metals, vol. 85, no. 1, pp. 1333-1334, 1997.

[21] K. Shahapurkar, C. D. Garcia, M. Doddamani, G. C. Mohan Kumar, and P. Prabhakar, "Compressive behavior of cenosphere/epoxy syntactic foams in arctic conditions," Composites Part B: Engineering, vol. 135, pp. 253-262, 2018.

[22] K. Shahapurkar, V. B. Chavan, M. Doddamani, and G. C. M. Kumar, "Influence of surface modification on wear behavior of fly ash cenosphere/epoxy syntactic foam," Wear, vol. 414-415, pp. 327-340, 2018.

[23] K. Shahapurkar, M. Doddamani, G. C. Mohan Kumar, and N. Gupta, "Effect of cenosphere filler surface treatment on the erosion behavior of epoxy matrix syntactic foams," Polymer Composites, vol. 40, no. 6, pp. 2109-2118, 2019.

[24] C. D. Garcia, K. Shahapurkar, M. Doddamani, G. C. M. Kumar, and P. Prabhakar, "Effect of arctic environment on flexural behavior of fly ash cenosphere reinforced epoxy syntactic foams," Composites Part B: Engineering, vol. 151, pp. 265-273, 2018.

[25] G. Yang, Y. Wang, H. Xu, S. Zhou, S. Jia, and J. Zang, "Preparation and properties of three dimensional graphene/ phenolic resin composites via in-situ polymerization in graphene hydrogels," Applied Surface Science, vol. 447, pp. 837-844, 2018.

[26] G. Christopher, M. Anbu Kulandainathan, and G. Harichandran, "Comparative study of effect of corrosion on mild steel with waterborne polyurethane dispersion containing graphene oxide versus carbon black nanocomposites," Progress in Organic Coatings, vol. 89, pp. 199211, 2015.

[27] L. Liu and Z. Ye, "Effects of modified multi-walled carbon nanotubes on the curing behavior and thermal stability of boron phenolic resin," Polymer Degradation and Stability, vol. 94, no. 11, pp. 1972-1978, 2009.
[28] S. A. Song, Y. S. Chung, and S. S. Kim, "The mechanical and thermal characteristics of phenolic foams reinforced with carbon nanoparticles," Composites Science and Technology, vol. 103, pp. 85-93, 2014.

[29] G. Bahlakeh, B. Ramezanzadeh, and M. Ramezanzadeh, "Cerium oxide nanoparticles influences on the binding and corrosion protection characteristics of a melamine-cured polyester resin on mild steel: an experimental, density functional theory and molecular dynamics simulation study," Corrosion Science, vol. 118, pp. 69-83, 2017.

[30] O. Dagdag, A. El Harfi, A. Essamri et al., "Phosphorous-based epoxy resin composition as an effective anticorrosive coating for steel," International Journal of Integrated Care, vol. 9, no. 3, pp. 231-240, 2018. 